\title{
OPTIMALISASI KEUNTUNGAN PRODUK CAKE DENGAN METODE SIMPLEKS
}

\author{
Aden*, Tabah Heri Setiawan \\ Jurusan Matematika, Universitas Pamulang \\ ${ }^{*}$ Corresponding Author Email: dosen00527@unpam.ac.id
}

\begin{abstract}
Simplex is an optimization analysis method used to find out the maximum gross results. The purpose of this study is know the form of mathematical models that are formed from the production process of muffins, using a simplex method to determine the optimal profit, and the optimal amount of muffins production. Research methods using survey methods. The results obtained are by the simplex analysis, which is a mathematical model with the objective function$$
f\left(B_{1}, B_{2}, B_{3}, B_{4}, B_{5}, B_{6}, B_{7}, B_{8}, B_{9}, B_{10}\right)
$$$$
=6000 B_{1}+5000 B_{1}+5000 B_{3}+5000 B_{4}+5400 B_{5}+6400 B_{6}
$$$$
+7200 B_{7}+6000 B_{8}+6400 B_{9}+6400 B_{10}
$$$$
\text { Constraints function }
$$

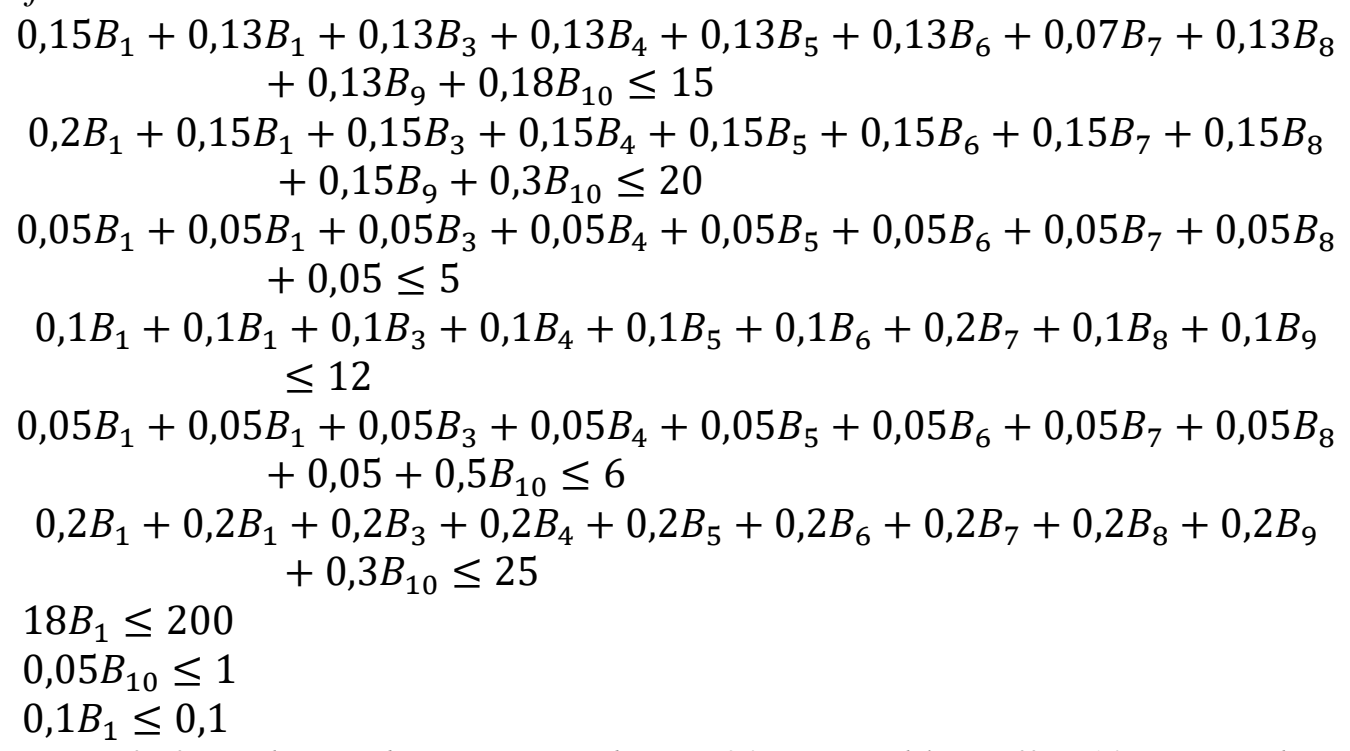

The maximum profit from the production is producing 90 pcs marble muffin, 10 pcs Surabaya muffin and 10 pcs Lapis legit muffin with a profit of $R p$ 714,000.00.

Keywords: optimization, simplex

\begin{abstract}
ABSTRAK
Simpleks merupakan metode analisis optimalisasi yang digunakan untuk mengetahui hasil bruto yang maksimal. Tujuan penelitian ini yaitu mengetahui bentuk model matematika yang terbentuk dari proses produksi bolu, mengetahui keuntungan yang optimal dengan menggunakan metode simpleks, dan mengetahui jumlah produksi bolu yang di produksi sehingga mendapatkan keuntungan yang optimal. Metode penelitian dengan menggunakan metode Survei. Hasil yang diperoleh sesuai analisis simpleks yaitu model matematika dengan fungsi tujuan
\end{abstract}




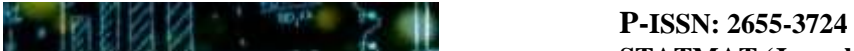

$$
\begin{aligned}
& \text { StatMat } \\
& \text { STATMAT (Jurnal Statistik dan Matematika), Vol. 2, No. 1, } 2020 \\
& \text { Halaman: 34-44 } \\
& \text { @Prodi S-1 Matematika FMIPA Unpam } \\
& f\left(B_{1}, B_{2}, B_{3}, B_{4}, B_{5}, B_{6}, B_{7}, B_{8}, B_{9}, B_{10}\right) \\
& =6000 B_{1}+5000 B_{1}+5000 B_{3}+5000 B_{4}+5400 B_{5}+6400 B_{6} \\
& +7200 B_{7}+6000 B_{8}+6400 B_{9}+6400 B_{10} \\
& 0,15 B_{1}+0,13 B_{1}+0,13 B_{3}+0,13 B_{4}+0,13 B_{5}+0,13 B_{6}+0,07 B_{7}+0,13 B_{8} \\
& +0,13 B_{9}+0,18 B_{10} \leq 15 \\
& 0,2 B_{1}+0,15 B_{1}+0,15 B_{3}+0,15 B_{4}+0,15 B_{5}+0,15 B_{6}+0,15 B_{7}+0,15 B_{8} \\
& +0,15 B_{9}+0,3 B_{10} \leq 20 \\
& 0,05 B_{1}+0,05 B_{1}+0,05 B_{3}+0,05 B_{4}+0,05 B_{5}+0,05 B_{6}+0,05 B_{7}+0,05 B_{8} \\
& +0,05 \leq 5 \\
& 0,1 B_{1}+0,1 B_{1}+0,1 B_{3}+0,1 B_{4}+0,1 B_{5}+0,1 B_{6}+0,2 B_{7}+0,1 B_{8}+0,1 B_{9} \\
& \leq 12 \\
& 0,05 B_{1}+0,05 B_{1}+0,05 B_{3}+0,05 B_{4}+0,05 B_{5}+0,05 B_{6}+0,05 B_{7}+0,05 B_{8} \\
& +0,05+0,5 B_{10} \leq 6 \\
& 0,2 B_{1}+0,2 B_{1}+0,2 B_{3}+0,2 B_{4}+0,2 B_{5}+0,2 B_{6}+0,2 B_{7}+0,2 B_{8}+0,2 B_{9} \\
& +0,3 B_{10} \leq 25 \\
& 18 B_{1} \leq 200 \\
& 0,05 B_{10} \leq 1 \\
& 0,1 B_{1} \leq 0,1
\end{aligned}
$$

Maksimum keuntungan dari hasil produksi yaitu memproduksi Bolu Marmer 90 pcs, Bolu Surabaya 10 pcs dan bolu Lapis legit 10 pcs dengan keuntungan Rp 714.000,00.

\section{Kata kunci: optimalisasi, simpleks}

\section{PENDAHULUAN}

Keuntungan penjualan sebuah produk sangat ditentukan dengan kesesuaian varian yang diproduksi oleh industri. Semakin tidak sesuai yang diproduksi maka akan mengakibatkan kerugian dari penjualan produk yang diproduksi. Tetapi jika produksi dengan bentuk varian sesuai dengan kebutuhan pasar maka akan mengakibatkan keuntungan penjualan baik dan semakin baik.

Pencatatan secara detail setiap proses produksi roti untuk lebih mengetahui proses supaya kualitas semakin lebih meningkat (Aden, 2019). Planing yang matang untuk sebuah produksi produk akan menjadikan langkah menuju detailisasi pembuatan produk dari hulu hingga hilir. Sehingga bahan baku yang baik akan menjadikan produk baik. Sebaliknya bahan baku yang kurang baik akan menjadikan hasil produksi yang kurang baik juga. Ukuran bahan baku yang sangat detail akan menjadikan perhitunagn analisis semakin baik. Menentukan kualitas produk yang sesuai dengan kesepakatan diawal sehingga akan memuaskan pelanggan. (Waryanto, H., \& Setiawan, T. H., 2019)

Jumlah yang tidak diprediksikan dan dianalisis akan menjadikan produk berlebih dan akan menjadi produk yang sia-sia. Penjualan yang tidak optimal akan menjadikan kerugian yang berarti bahwa keuntungan belum optimal sesuai harapan. Sebaliknya jika diprediksikan 
dan dianalisis dengan baik maka akan menjadikan produk tidak jauh dari kebutuhan sehingga produk tidak tersisa signifikan bahkan tepat. Sehingga keuntungan yang diperoleh akan lebih optimal sesuai yang diharapkan.

Penyelesaian masalah di atas dapat diselesaikan dengan metode program linier denngan metode grafik, eliminasi, substitusi dan simpleks. Jika sedikit variabelnya maka dapat diselesaikan dengan menggunakan metode grafik, substitusi, dan eliminasi. Sedangkan jika variabelnya banyak dan kendalanya banyak maka lebih tepat menggunakan metode simpleks untuk mendapatkan hasil yang lebih tepat.

Metode yang dipilih dalam penelitian ini yaitu metode simpleks. Metode simpleks yaitu metode penyelesaian program linier dengan banyak variabel dan banyak kendala dengan langkah iterasi yang disesuaikan dengan bentuk tujuan dan kendala serta hasilnya. Metode simpleks dapat dibantu penyelesaiannya dengan menggunakan POM QM for windows dan Excel. Sehingga dengan metode ini peneliti dapat menemukan jumlah produksi dengan keuntungan yang seoptimal mungkin.

Sesuai dengan latar belakang yang telah disebutkan di atas, maka peneliti akan melakukan penelitian yang berjudul "Optimalisasi Keuntungan Produk Cake dengan Metode Simpleks".

\subsection{Rumusan Masalah}

Perumusan masalah dalam penelitian ini adalah:

1. Bagaimana bentuk model matematika yang terbentuk dari proses produksi bolu?

2. Berapakah keuntungan yang optimal dengan menggunakan metode simpleks?

3. Berapakah jumlah produksi bolu yang di produksi sehingga mendapatkan keuntungan yang optimal?

\subsection{Tujuan Penelitian}

Tujuan penelitian yang dilaksanakan yaitu:

1. Mengetahui bentuk model matematika yang terbentuk dari proses produksi bolu.

2. Mengetahui keuntungan yang optimal dengan menggunakan metode simpleks.

3. Mengetahui jumlah produksi bolu yang di produksi sehingga mendapatkan keuntungan yang optimal. 


\section{METODOLOGI PENELITIAN}

\subsection{Metode Penelitian}

Metode penelitian merupakan suatu penyelidikan yang sistematis untuk meningkatkan sejumlah pengetahuan, juga merupakan suatu usaha yang sistematis dan terorganisasi untuk menyelidiki masalah tertentu yang memerlukan jawaban. Metode penelitian kuantitatif dapat diartikan sebagai metode penelitian yang berlandaskan pada filsafat positivisme, digunakan untuk meneliti pada populasi dan sampel tertentu, pengumpulan data menggunakan instrumen penelitian, analisis data bersifat kuantitatif atau statistik, dengan tujuan untuk menguji hipotesis yang telah ditetapkan (Sugiyono, 2016). Metode penelitian pada penelitian ini menggunakan metode kuantitatif karena berbentuk data angka-angka.

\subsection{Populasi dan Sampel Penelitian}

Populasi dan sampel merupakan dua hal yang saling berhubungan yang tidak dapat terpisahkan dalam sebuah penelitian. Jika populasi dengan sampel tidak saling berhubungan dan tidak proporsional maka dianggap sebuah penelitian tersebut belum akurat untuk dapat diambil kesimpulan.

\subsection{Metode Penentuan Populasi}

Totalitas semua nilai yang mungkin, hasil menghitung maupun pengukuran, kuantitatif maupun kualitatif mengenai karakteristik tertentu dari semua anggota kumpulan yang lengkap dan jelas yang ingin dipelajari sifat-sifatnya dinamakan dengan populasi (Sudjana, 2005). Populasi yaitu sekumpulan objek yang akan dijadikan sebagai bahan penelitian dengan ciri mempunyai karaktristik yang sama. (Andi Supangat, 2007). Populasi dapat berupa benda hidup atau mati yang mempunyai karakteristik yanng dapat didefinisikan atau diidentifikasi dengan jelas. Populasi dalam penelitian ini adalah data produksi Cake dan bahan mentah setiap bulan.

\subsection{Metode Penentuan Sampel}

Sampel yaitu bagian dari populasi untuk dijadikan sebagai bahan penelaahanndengan harapan contoh yang diambil dari populasi tersebut dapat mewakili terhadap populasi (Andi Supangat, 2007). Sampel adalah bagian dari jumlah dan karakteristik yang dimiliki populasi (Sugiyono, 2012). Sampel merupakan bagian dari populasi yang diambil sebagian secara proporsional sesuai dengan metode yang telah ditetapkan oleh peniliti dalam menentukan jumlah sampel. Untuk mendapatkan sampel digunakan teknik sampel terstruktur. Data sampel pada penelitian ini data yang diambil secara survei dan wawancara dengan bentuk 
tujuan keuntungan, bahan yang tersedia dan jenis bolu.

\subsection{Metode Pengolahan Data}

Pengolahan data pada penelitian ini dilakukan dalam bentuk manual. Langkahlangkah perhitungan pengolahan data dalam penelitian ini yaitu:

1. Mengumpulkan data dengan cara survei dan wawancara;

2. Membuatkan model matematis baik tujuan kendalanya;

3. Membuat dalam bentuk tabel simpleks;

4. Menghitung dengan metode simpleks sehingga terjadi beberapa iterasi yang menuju optimalisasi keuntungan;

5. Menentukan jumlah keuntungan;

6. Menentukan jumlah produk yang menjadikan keuntungan yang optimal;

7. Membandingkan keuntungan metode simpleks dengan metode yang telah dijalankan di Karoma Cake; dan

8. Membuat kesimpulan.

\section{HASIL DAN PEMBAHASAN}

\subsection{Data Hasil Penelitian}

Data penelitian diperoleh dengan menggunkan metode survei dan wawancara kepada karyawan dan pemilik UKM Karoma Cake. Data penelitian awal yaitu data produksi bolu dengan rincian sebagai berikut:

1. Bolu Brownies memerlukan terigu 1,5 kg, gula putih $2 \mathrm{~kg}$, benzoat $1 / 2$ sendok, paneli 1 sendok, soda kue $1 / 2$ sendok, telor $2 \mathrm{~kg}$, dan kokoa $180 \mathrm{mg}$ untuk dijadikan 16 bolu brownies dalam produksi 1 hari.

2. Bolu tape memerlukan terigu $1,3 \mathrm{~kg}$, gula putih $1,5 \mathrm{~kg}$, benzoat $1 / 2$ sendok, paneli 1 sendok, soda kue $1 / 2$ sendok, dan telor $2 \mathrm{~kg}$ untuk dijadikan 10 bolu tape dalam produksi 1 hari.

3. Bolu pisang memerlukan terigu $1,3 \mathrm{~kg}$, gula putih $1,5 \mathrm{~kg}$, benzoat $1 / 2$ sendok, paneli 1 sendok, soda kue $1 \frac{1}{2}$ sendok, dan telor $2 \mathrm{~kg}$ untuk dijadikan 10 bolu pisang dalam produksi 1 hari.

4. Bolu keju memerlukan terigu $1,3 \mathrm{~kg}$, gula putih $1,5 \mathrm{~kg}$, benzoat $1 / 2$ sendok, paneli 1 sendok, soda kue $1 / 2$ sendok, dan telor $2 \mathrm{~kg}$ untuk dijadikan 10 bolu keju dalam produksi 1 hari. 
5. Bolu pandan memerlukan terigu $1,3 \mathrm{~kg}$, gula putih $1,5 \mathrm{~kg}$, benzoat $1 / 2$ sendok, paneli 1 sendok, soda kue $1 / 2$ sendok, dan telor $2 \mathrm{~kg}$ untuk dijadikan 10 bolu pandan dalam produksi 1 hari.

6. Bolu marmer memerlukan terigu $1,3 \mathrm{~kg}$, gula putih $1,5 \mathrm{~kg}$, benzoat $1 / 2$ sendok, paneli 2 sendok, soda kue $1 / 2$ sendok, dan telor $2 \mathrm{~kg}$ untuk dijadikan 10 bolu marmer dalam produksi 1 hari.

7. Bolu surabaya memerlukan terigu $0,7 \mathrm{~kg}$, gula putih $1 \mathrm{~kg}$, benzoat $1 / 2$ sendok, paneli 1 sendok, soda kue $1 / 2$ sendok, dan telor $2 \mathrm{~kg}$ untuk dijadikan 4 bolu surabaya dalam produksi 1 hari.

8. Bolu ketan item memerlukan terigu 1,3 kg, gula putih $1,5 \mathrm{~kg}$, benzoat $1 / 2$ sendok, paneli 1 sendok, soda kue $1 / 2$ sendok, dan telor $2 \mathrm{~kg}$ untuk dijadikan 10 bolu ketan item dalam produksi 1 hari.

9. Bolu tiga rasa memerlukan terigu $1,3 \mathrm{~kg}$, gula putih $1,5 \mathrm{~kg}$, benzoat $1 / 2$ sendok, paneli 1 sendok, soda kue $1 / 2$ sendok, dan telor $2 \mathrm{~kg}$ untuk dijadikan 10 bolu tiga rasa dalam produksi 1 hari.

10. Bolu lapis legit memerlukan terigu $1,8 \mathrm{~kg}$, gula putih $3 \mathrm{~kg}$, paneli 1 sendok, soda kue $1 / 2$ sendok, telor $3 \mathrm{~kg}$, pewarna $1 / 2$ sendok dan kayu manis $1 / 2$ sendok untuk dijadikan 12 bolu lapis legit dalam produksi 1 hari.

Persedian bahan mentah dalam 1 hari yaitu

1. Terigu $15 \mathrm{~kg}$

2. Gula putih $20 \mathrm{~kg}$

3. Benzoat 5 sendok

4. Paneli 12 sendok

5. Soda kue 6 sendok

6. Telor $25 \mathrm{~kg}$

7. Kokoa $200 \mathrm{mg}$

8. Pewarna 2 sendok

9. Kayu manis 2 sendok

Harga penjualan yaitu:

1. Bolu brownies dengan harga Rp 30.000,00

2. Bolu tape dengan harga $\operatorname{Rp} 25.000,00$

3. Bolu pisang dengan harga $\mathrm{Rp} 25.000,00$ 
4. Bolu keju dengan harga Rp 25.000,00

5. Bolu pandan dengan harga $\mathrm{Rp} 27.000,00$

6. Bolu marmer dengan harga Rp 32.000,00

7. Bolu surabaya dengan harga $\mathrm{Rp} 36.000,00$

8. Bolu ketan item dengan harga Rp 30.000,00

9. Bolu tiga rasa dengan harga $\mathrm{Rp} 32.000,00$

10. Bolu lapis legit dengan harga $\operatorname{Rp} 32.000,00$

Dengan keuntungan dari penjualan sebesar $20 \%$.

\subsection{Hasil Analisis dengan Metode Simpleks}

\subsubsection{Model matematika}

Untuk jenis bolu dimisalkan B sehingga ada 10 variabel yaitu B1 sampai B10. Sedangkan untuk jenis bahan mentah dimisalkan dengan $M$ sehingga terdapat 9 variabel yaitu M1 sampai dengan M9. Model matematika yang terbentuk yaitu:

Fungsi tujuan

$$
\begin{aligned}
f\left(B_{1}, B_{2}, B_{3}, B_{4}, B_{5}, B_{6}, B_{7}, B_{8}, B_{9}, B_{10}\right) \\
=6000 B_{1}+5000 B_{1}+5000 B_{3}+5000 B_{4}+5400 B_{5}+6400 B_{6} \\
+7200 B_{7}+6000 B_{8}+6400 B_{9}+6400 B_{10}
\end{aligned}
$$

Fungsi kendala

$$
\begin{aligned}
& 0,15 B_{1}+0,13 B_{1}+0,13 B_{3}+0,13 B_{4}+0,13 B_{5}+0,13 B_{6}+0,07 B_{7}+0,13 B_{8} \\
& +0,13 B_{9}+0,18 B_{10} \leq 15 \\
& 0,2 B_{1}+0,15 B_{1}+0,15 B_{3}+0,15 B_{4}+0,15 B_{5}+0,15 B_{6}+0,15 B_{7}+0,15 B_{8} \\
& +0,15 B_{9}+0,3 B_{10} \leq 20 \\
& 0,05 B_{1}+0,05 B_{1}+0,05 B_{3}+0,05 B_{4}+0,05 B_{5}+0,05 B_{6}+0,05 B_{7}+0,05 B_{8} \\
& +0,05 \leq 5 \\
& 0,1 B_{1}+0,1 B_{1}+0,1 B_{3}+0,1 B_{4}+0,1 B_{5}+0,1 B_{6}+0,2 B_{7}+0,1 B_{8}+0,1 B_{9} \\
& \leq 12 \\
& 0,05 B_{1}+0,05 B_{1}+0,05 B_{3}+0,05 B_{4}+0,05 B_{5}+0,05 B_{6}+0,05 B_{7}+0,05 B_{8} \\
& +0,05+0,5 B_{10} \leq 6 \\
& 0,2 B_{1}+0,2 B_{1}+0,2 B_{3}+0,2 B_{4}+0,2 B_{5}+0,2 B_{6}+0,2 B_{7}+0,2 B_{8}+0,2 B_{9} \\
& +0,3 B_{10} \leq 25 \\
& 18 B_{1} \leq 200 \\
& 0,05 B_{10} \leq 1
\end{aligned}
$$




$$
0,1 B_{1} \leq 0,1
$$

\subsubsection{Pembuatan tabel simpleks}

Tabel 1 Proses Awal Tabel Simpleks

\begin{tabular}{|c|c|c|c|c|c|c|c|c|c|c|c|}
\hline \multirow{2}{*}{$\begin{array}{c}\text { JENIS } \\
\text { BAHAN }\end{array}$} & \multicolumn{10}{|c|}{ JENIS PRODUKSI } & \multirow{2}{*}{ PERSEDIAAN } \\
\hline & B1 & $\mathrm{B} 2$ & B3 & B4 & B5 & B6 & B7 & B8 & B9 & $\mathrm{B} 10$ & \\
\hline M1 & 0,15 & 0,13 & 0,13 & 0,13 & 0,13 & 0,13 & 0,07 & 0,13 & 0,13 & 0,18 & 15 \\
\hline M2 & 0,2 & 0,15 & 0,15 & 0,15 & 0,15 & 0,15 & 0,15 & 0,15 & 0,15 & 0,3 & 20 \\
\hline M3 & 0,05 & 0,05 & 0,05 & 0,05 & 0,05 & 0,05 & 0,05 & 0,05 & 0,05 & 0 & 5 \\
\hline M4 & 0,1 & 0,1 & 0,1 & 0,1 & 0,1 & 0,1 & 0,2 & 0,1 & 0,1 & 0,1 & 12 \\
\hline M5 & 0,05 & 0,05 & 0,05 & 0,05 & 0,05 & 0,05 & 0,05 & 0,05 & 0,05 & 0,05 & 6 \\
\hline M6 & 0,2 & 0,2 & 0,2 & 0,2 & 0,2 & 0,2 & 0,2 & 0,2 & 0,2 & 0,3 & 25 \\
\hline M7 & 18 & 0 & 0 & 0 & 0 & 0 & 0 & 0 & 0 & 0 & 200 \\
\hline M8 & 0 & 0 & 0 & 0 & 0 & 0 & 0 & 0 & 0 & 0,05 & 1 \\
\hline M9 & 0 & 0 & 0 & 0 & 0 & 0 & 0 & 0 & 0 & 0,1 & 0,1 \\
\hline
\end{tabular}

\subsubsection{Hasil Simpleks}

Pembuatan simpleks dengan mengubah dari model matematika menjadi bentuk model simpleks

Fungsi tujuan:

$$
f\left(B_{1}, B_{2}, B_{3}, B_{4}, B_{5}, B_{6}, B_{7}, B_{8}, B_{9}, B_{10}\right)=z
$$

Sehingga model simpleksnya:

$$
\begin{aligned}
z-000 B_{1}- & 5000 B_{1}-5000 B_{3}-5000 B_{4}-5400 B_{5}-6400 B_{6}-7200 B_{7}-6000 B_{8} \\
- & 6400 B_{9}-6400 B_{10}-0 S_{1}-0 S_{2}-0 S_{2}-0 S_{3}-0 S_{4}-0 S_{5}-0 S_{6}-0 S_{7} \\
- & 0 S_{8}-0 S_{9}-0 S_{10}=0
\end{aligned}
$$

Fungsi kendala:

$$
\begin{aligned}
0,15 B_{1}+0,13 & B_{1}+0,13 B_{3}+0,13 B_{4}+0,13 B_{5}+0,13 B_{6}+0,07 B_{7}+0,13 B_{8}+0,13 B_{9} \\
+ & 0,18 B_{10}+S_{1}+0 S_{2}+0 S_{2}+0 S_{3}+0 S_{4}+0 S_{5}+0 S_{6}+0 S_{7}+0 S_{8}+0 S_{9} \\
+ & 0 S_{10}=15 \\
0,2 B_{1}+0,15 B_{1} & +0,15 B_{3}+0,15 B_{4}+0,15 B_{5}+0,15 B_{6}+0,15 B_{7}+0,15 B_{8}+0,15 B_{9} \\
& +0,3 B_{10}+0 S_{1}+S_{2}+0 S_{2}+0 S_{3}+0 S_{4}+0 S_{5}+0 S_{6}+0 S_{7}+0 S_{8}+0 S_{9} \\
& +0 S_{10}=20 \\
0,05 B_{1}+0,05 & B_{1}+0,05 B_{3}+0,05 B_{4}+0,05 B_{5}+0,05 B_{6}+0,05 B_{7}+0,05 B_{8}+0,05 B_{9} \\
& +0,05 B_{10}+0 S_{1}+0 S_{2}+S_{3}+0 S_{4}+0 S_{5}+0 S_{6}+0 S_{7}+0 S_{8}+0 S_{9} \\
& +0 S_{10}=5
\end{aligned}
$$




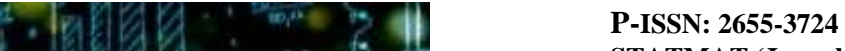

$$
\begin{aligned}
& \text { StatMat } \\
& \text { STATMAT (Jurnal Statistik dan Matematika), Vol. 2, No. 1, } 2020 \\
& \text { Halaman: 34-44 } \\
& \text { @Prodi S-1 Matematika FMIPA Unpam } \\
& 0,1 B_{1}+0,1 B_{1}+0,1 B_{3}+0,1 B_{4}+0,1 B_{5}+0,1 B_{6}+0,2 B_{7}+0,1 B_{8}+0,1 B_{9}+0,1 B_{10} \\
& +0 S_{1}+0 S_{2}+0 S_{2}+0 S_{3}+S_{4}+0 S_{5}+0 S_{6}+0 S_{7}+0 S_{8}+0 S_{9}+0 S_{10} \\
& =12 \\
& 0,05 B_{1}+0,05 B_{1}+0,05 B_{3}+0,05 B_{4}+0,05 B_{5}+0,05 B_{6}+0,05 B_{7}+0,05 B_{8}+0,05 \\
& +0,5 B_{10}+0 S_{1}+0 S_{2}+0 S_{2}+S_{3}+0 S_{4}+S_{5}+0 S_{6}+0 S_{7}+0 S_{8}+0 S_{9} \\
& +0 S_{10}=6 \\
& 0,2 B_{1}+0,2 B_{1}+0,2 B_{3}+0,2 B_{4}+0,2 B_{5}+0,2 B_{6}+0,2 B_{7}+0,2 B_{8}+0,2 B_{9}+0,3 B_{10} \\
& +0 S_{1}+0 S_{2}+0 S_{2}+0 S_{3}+0 S_{4}+0 S_{5}+S_{6}+0 S_{7}+0 S_{8}+0 S_{9}+0 S_{10} \\
& =25 \\
& 18 B_{1}+0 S_{1}+0 S_{2}+0 S_{2}+0 S_{3}+0 S_{4}+0 S_{5}+0 S_{6}+S_{7}+0 S_{8}+0 S_{9}+0 S_{10}=200 \\
& 0,05 B_{10}+0 S_{1}+0 S_{2}+0 S_{2}+0 S_{3}+0 S_{4}+0 S_{5}+0 S_{6}+0 S_{7}+S_{8}+0 S_{9}+0 S_{10}=1 \\
& 0,1 B_{1}+0 S_{1}+0 S_{2}+1 S_{2}+0 S_{3}+0 S_{4}+0 S_{5}+0 S_{6}+0 S_{7}+0 S_{8}+S_{9}+0 S_{10}=0,1
\end{aligned}
$$

\subsubsection{Hasil Iterasi Maksimum dari Simpleks}

Proses analisis data dengan menggunakan Simpleks untuk data produksi Bolu di Karoma Cake sampai dengan 4 iterasi. Sehingga diperoleh hasil maksimumnya disajikan pada Tabel 2.

Tabel 2 Hasil Iterasi Maksimum

\begin{tabular}{|l|r|r|r|r|r|r|r|r|r|r|r|r|}
\hline & $B 1$ & $B 2$ & $B 3$ & $B 4$ & $B 5$ & $B 6$ & $B 7$ & $B 8$ & $B 9$ & $B 10$ & & RHS \\
\hline Maximize & 6000 & 5000 & 5000 & 5000 & 5400 & 6400 & 7200 & 6000 & 6400 & 6400 & & \\
\hline M1 & .15 & .13 & .13 & .13 & .13 & .13 & .07 & .13 & .13 & .18 & $<=$ & 15 \\
\hline M2 & .2 & .15 & .15 & .15 & .15 & .15 & .15 & .15 & .15 & .3 & $<=$ & 20 \\
\hline M3 & .05 & .05 & .05 & .05 & .05 & .05 & .05 & .05 & .05 & 0 & $<=$ & 5 \\
\hline M4 & .1 & .1 & .1 & .1 & .1 & .1 & .2 & .1 & .1 & .1 & $<=$ & 12 \\
\hline M5 & .05 & .05 & .05 & .05 & .05 & .05 & .05 & .05 & .05 & .05 & $<=$ & 6 \\
\hline M6 & .2 & .2 & .2 & .2 & .2 & .2 & .2 & .2 & .2 & .3 & $<=$ & 25 \\
\hline M7 & 18 & 0 & 0 & 0 & 0 & 0 & 0 & 0 & 0 & 0 & $<=$ & 200 \\
\hline M8 & 0 & 0 & 0 & 0 & 0 & 0 & 0 & 0 & 0 & .05 & $<=$ & 1 \\
\hline M9 & 0 & 0 & 0 & 0 & 0 & 0 & 0 & 0 & 0 & .1 & $<=$ & 1 \\
\hline Solution- $>$ & 0 & 0 & 0 & 0 & 0 & 90 & 10 & 0 & 0 & 10 & \\
\hline
\end{tabular}

Berdasarkan Tabel 2 diperoleh bahwa B6 dengan bentuk produksi Bolu Marmer dengan jumlah 90 pcs, B7 bentuk produksi Bolu Surabaya dengan jumlah 10 pcs dan B10 bentuk produksi Bolu lapis legit dengan jumlah 10. Jumlah keuntungan maksimum Rp $712.000,00$. 


\section{KESIMPULAN}

Berdasarkan hasil data penelitian dan pembahasan, maka peneliti menyimpulkan sebagai berikut:

1. Bentuk model matematika yang terbetuk diperoleh dari produksi per hari dengan banyak awal produksi masing-masing bolu berbeda dengan bahan dasar yang berbeda. Persedian yang berbeda setiap bahan sehingga model matematika dapat diperoleh sebagai Fungsi tujuan

$$
\begin{aligned}
f\left(B_{1}, B_{2}, B_{3}, B_{4},\right. & \left.B_{5}, B_{6}, B_{7}, B_{8}, B_{9}, B_{10}\right) \\
& =6000 B_{1}+5000 B_{1}+5000 B_{3}+5000 B_{4}+5400 B_{5}+6400 B_{6} \\
& +7200 B_{7}+6000 B_{8}+6400 B_{9}+6400 B_{10}
\end{aligned}
$$

Dan Fungsi kendala

$$
\begin{aligned}
& 0,15 B_{1}+0,13 B_{1}+0,13 B_{3}+0,13 B_{4}+0,13 B_{5}+0,13 B_{6}+0,07 B_{7}+0,13 B_{8} \\
& +0,13 B_{9}+0,18 B_{10} \leq 15 \\
& 0,2 B_{1}+0,15 B_{1}+0,15 B_{3}+0,15 B_{4}+0,15 B_{5}+0,15 B_{6}+0,15 B_{7}+0,15 B_{8} \\
& +0,15 B_{9}+0,3 B_{10} \leq 20 \\
& 0,05 B_{1}+0,05 B_{1}+0,05 B_{3}+0,05 B_{4}+0,05 B_{5}+0,05 B_{6}+0,05 B_{7}+0,05 B_{8} \\
& +0,05 \leq 5 \\
& 0,1 B_{1}+0,1 B_{1}+0,1 B_{3}+0,1 B_{4}+0,1 B_{5}+0,1 B_{6}+0,2 B_{7}+0,1 B_{8}+0,1 B_{9} \\
& \leq 12 \\
& 0,05 B_{1}+0,05 B_{1}+0,05 B_{3}+0,05 B_{4}+0,05 B_{5}+0,05 B_{6}+0,05 B_{7}+0,05 B_{8} \\
& +0,05+0,5 B_{10} \leq 6 \\
& 0,2 B_{1}+0,2 B_{1}+0,2 B_{3}+0,2 B_{4}+0,2 B_{5}+0,2 B_{6}+0,2 B_{7}+0,2 B_{8}+0,2 B_{9} \\
& +0,3 B_{10} \leq 25
\end{aligned}
$$$$
18 B_{1} \leq 200
$$$$
0,05 B_{10} \leq 1
$$$$
0,1 B_{1} \leq 0,1
$$

2. Hasil optimum keuntungan yang diperoleh dengan menggunakan metode simpleks yaitu Rp 714.000,00.

3. Produksi yang menjadikan keuntungan maksimum yaitu produksi Bolu Marmer 90 pcs, Bolu Surabaya 10 pcs dan bolu Lapis legit 10 pcs. 


\section{DAFTAR PUSTAKA}

Aden, Setiawan TH. 2019. Analisis Pengendalian Kualitas Produk Roti Melalui Kartu Kendali Proporsi (Studi Kasus: CV. Spesial Bakery). Statmat: Jurnal Statistika Dan Matematika, 1(1): 25-43.

Sudjana. 2005. Metode Statistika. Taksiti, Bandung.

Sugiyono. 2012. Statistik untuk Penelitian. Alfabetha, Bandung.

Sugiyono. 2016. Metode Penelitian Kuantitatif, Kualitatif, dan R\&D. Alfabetha, Bandung. Supangat, Andi. 2007. Statistika dalam Kajian Deskriptif, Inferensi, dan Nonparametrik. Kencana, Jakarta.

Waryanto H, Setiawan TH. 2019. Statistik Pengendalian Kualitas. UNPAM Press, Tangerang Selatan. 